\title{
MODIFIKASI METODE NEWTON DENGAN KONVERGENSI ORDE TIGA UNTUK MENYELESAIKAN SISTEM PERSAMAAN NONLINEAR
}

\author{
Yuli Rahayu, Evi Noviani, Yudhi
}

\section{INTISARI}

\begin{abstract}
Metode Newton merupakan metode iterasi yang digunakan untuk mencari akar-akar persamaan nonlinear maupun sistem persamaan nonlinear dengan orde konvergensi dua. Pada penelitian ini dibahas tentang penyelesaian sistem persamaan nonlinear dengan modifikasi metode Newton. Metode yang diperoleh dengan modifikasi metode Newton mempunyai orde konvergensi tiga. Langkah-langkah untuk mencari solusi sistem persamaan nonlinear $\boldsymbol{F}(\boldsymbol{X})=\mathbf{0}$ dengan menggunakan metode ini adalah mencari nilai $\boldsymbol{X}_{\boldsymbol{n}}$ sebagai solusi dari iterasi ke-n dengan toleransi error $\left\|\boldsymbol{E}_{\boldsymbol{n}}\right\|<E_{\delta}$. Hasil penelitian menunjukkan bahwa metode tersebut dapat menyelesaikan sistem persamaan nonlinear dengan orde konvergensi tiga.
\end{abstract}

Kata kunci: Metode Newton, Orde konvergensi, Galat, Norm, Sistem Persamaan Nonlinear

\section{PENDAHULUAN}

Pada bidang ilmu pengetahuan sering muncul persoalan yang melibatkan model matematika. Sering kali model matematika yang muncul bukanlah suatu model yang sederhana, melainkan suatu model yang sulit untuk dicari penyelesaiannya. Model matematika ini bisa berupa suatu persamaan atau suatu sistem persamaan. Persamaan terdiri dari persamaan linear dan persamaan nonlinear. Sistem persamaan juga terdiri dari sistem persamaan linear dan sistem persamaan nonlinear.

Persamaan linear dengan $n$ variabel bebas $\left\{x_{1}, x_{2}, \ldots, x_{n}\right\}$ adalah persamaan yang berbentuk $y=a_{0}+a_{1} x_{1}+a_{2} x_{2}+\cdots+a_{n} x_{n}, a_{n} \neq 0, n \in \mathbb{N}$ Sedangkan persamaan nonlinear merupakan persamaan yang pangkat variabelnya bernilai lebih dari satu. Persamaan nonlinear sendiri dibagi menjadi persamaan nonlinear satu variabel dan persamaan nonlinear dengan $n$ variabel, dengan $n>1$. Bentuk umum persamaan nonlinear dengan satu variabel adalah $f(x)=0$ dengan $f(x)$ adalah fungsi nonlinear. Sedangkan bentuk umum persamaan nonlinear dengan $n$ variabel adalah $f\left(x_{1}, x_{2}, \ldots, x_{n}\right)=$ 0 dengan $f\left(x_{1}, x_{2}, \ldots, x_{n}\right)$ adalah fungsi nonlinear [1].

Sistem persamaan linear adalah himpunan $m$ persamaan linear dengan $m>1$. Sedangkan sistem persamaan nonlinear adalah himpunan $m$ persamaan nonlinear dengan $m>1$ yang dapat dinotasikan dengan $\mathbf{F}(\mathbf{x})=\mathbf{0}$. Secara umum, sistem persamaan nonlinear dapat diselesaikan dengan beberapa metode numerik, salah satunya adalah metode Newton. Metode Newton merupakan metode iterasi yang memiliki orde konvergensi kuadratik. Metode Newton dapat diperoleh dengan pendekatan secara geometri dan pendekatan dengan deret Taylor. Metode Newton digunakan untuk mencari hampiran atau pendekatan terhadap akar fungsi real pada persamaan nonlinear. Penentuan akar-akar persamaan merupakan salah satu persoalan yang terdapat dalam persamaan nonlinear. Metode Newton juga dapat menyelesaikan sistem persamaan nonlinear. Langkah awal penyelesaian sistem persamaan nonlinear dengan metode Newton adalah mencari turunan parsial semua fungsinya terhadap setiap variabel yang ada dalam sistem tersebut. Semua turunan parsial dalam sistem dibentuk menjadi suatu matriks yang dinamakan matriks Jacobian [1]. 
Modifikasi metode Newton dapat menyelesaikan persamaan nonlinear. Metode yang diperoleh dengan cara pendekatan kuadratur untuk menghampiri integral dan dapat menyelesaikan persamaan nonlinear dengan orde konvergensi tiga [2].

Pada penelitian ini membahas tentang analisis modifikasi metode Newton konvergensi orde tiga dalam menyelesaikan sistem persamaan nonlinear. Nilai galat tolerasi $\left(E_{\delta}\right)$ yang digunakan untuk menentukan solusi dari sistem persamaan nonlinear adalah $10^{-15}$.

\section{PERSAMAAN NONLINEAR DAN SISTEM PERSAMAAN NONLINEAR}

Secara umum semua persamaan berbentuk $f(x)=0$. Bentuk persamaan tersebut dikatakan nonlinear jika $f$ merupakan bentuk fungsi nonlinear dari variabel $\mathrm{x}$. Salah satu contoh bentuk persamaan nonlinear adalah sebagai berikut :

$$
f(x, y)=x y^{2}+x-10 y+8=0 .
$$

Penyelesaian persamaan nonlinear adalah penentuan akar-akar persamaan nonliniear, yang mana akar suatu persamaan $f(x)=0$ adalah nilai $x$ yang menyebabkan nilai $f(x)=0$ [3].

Sistem persamaan nonlinear adalah kumpulan dari persamaan nonlinear yang saling berkaitan yang berjumlah lebih dari satu persamaan [4]. Bentuk umum sistem persamaan nonlinear dengan $m$ persamaan dan $n$ variabel adalah :

$$
\begin{gathered}
f_{1}\left(x_{1}, x_{2}, \ldots, x_{n}\right)=0 \\
f_{2}\left(x_{1}, x_{2}, \ldots, x_{n}\right)=0 \\
\vdots \\
f_{m}\left(x_{1}, x_{2}, \ldots, x_{n}\right)=0
\end{gathered}
$$

dengan fungsi $f_{i} ; i=1,2, \ldots, m$ merupakan fungsi yang memetakan dari $\mathbb{R}^{n} \mathrm{ke} \mathbb{R}$. Sistem persamaan nonlinear juga dapat direpresentasikan dengan mendefinisikan fungsi $\mathbf{F}$, pemetaan $\mathbb{R}^{n}$ ke $\mathbb{R}^{n}$ sebagai berikut:

$\mathbf{F}\left(x_{1}, x_{2}, \ldots, x_{n}\right)=\left(f_{1}\left(x_{1}, x_{2}, \ldots, x_{n}\right), f_{2}\left(x_{1}, x_{2}, \ldots, x_{n}\right), \ldots, f_{m}\left(x_{1}, x_{2}, \ldots, x_{n}\right)\right)^{T}$.

Jika variabel $\mathbf{X}=\left(x_{1}, x_{2}, \ldots, x_{n}\right)^{T}$ merupakan suatu vektor yang digunakan untuk menjelaskan Persamaan (2) maka persamaan dapat ditulis dengan bentuk sebagai berikut:

$$
\mathbf{F}(\mathbf{X})=\mathbf{0} .
$$

Fungsi $f_{1}, f_{2}, \ldots, f_{m}$ disebut dengan koordinat fungsi dari $\mathbf{F}[4]$.

\section{METODE NEWTON}

Metode Newton merupakan salah satu metode iterasi yang digunakan untuk menyelesaikan permasalahan nonlinear. Secara umum metode Newton dikembangkan dari perluasan deret Taylor

$$
f(x)=f\left(x_{n}\right)+f^{\prime}\left(x_{n}\right)\left(x-x_{n}\right)+\frac{f^{\prime \prime}\left(x_{n}\right)}{2 !}\left(x-x_{n}\right)^{2}+\cdots+\frac{f^{n}\left(x_{n}\right)}{n !}\left(x-x_{n}\right)^{n}+\cdots .
$$

Pada sistem persamaan nonlinear, semua persamaan harus disamakan dengan nol [5]. Penyelesaian sistem persamaan nonlinear menggunakan perluasan metode Newton melalui ekspansi deret Taylor pada masing-masing persamaan, dengan ekspansi deret Taylor :

$$
f\left(x_{n+1}\right)=f\left(x_{n}\right)+\left(x_{n+1}-x_{n}\right) f^{\prime}\left(x_{n}\right) .
$$

Maka Persamaan (3) dapat disusun ulang menjadi :

$$
x_{n+1}=x_{n}-\frac{f\left(x_{n}\right)}{f^{\prime}\left(x_{n}\right)} .
$$


Iterasi dimulai dengan memberikan nilai awal untuk $x_{0}$. Iterasi akan berhenti apabila memenuhi pendekatan galat relatif $\left|x_{n+1}-x_{n}\right|<\varepsilon$, dengan $x_{n+1}$ merupakan nilai $x$ yang baru. Kekonvergenan ditentukan pada pemilihan tebakan awal. Tebakan yang terlalu jauh dari solusi akan menyebabkan iterasi divergen. Metode Newton merupakan metode iterasi yang memiliki konvergensi kuadratik [6].

\section{Konstruksi Modifikasi Metode Newton untuk Penyelesaian Persamaan Nonlinear}

Modifikasi metode Newton diperoleh dari pengembangan metode Newton dengan menambahkan satu langkah. Langkah pertama untuk mengkonstruksi modifikasi metode Newton dengan pendekatan integral, yaitu :

$$
f(x)=f\left(y_{n}\right)+\int_{y_{n}}^{x} f^{\prime}(t) d t
$$

dengan,

$$
y_{n}=x_{n}+\frac{f\left(x_{n}\right)}{f^{\prime}\left(x_{n}\right)}, \text { untuk } f^{\prime}\left(x_{n}\right) \neq 0 .
$$

Pandang Persamaan (5), yaitu bagian integral

$$
\int_{y_{n}}^{x} f^{\prime}(t) d t
$$

Bagian integral (6) dihampiri dengan metode titik tengah, yaitu

$$
\begin{aligned}
& \int_{y_{n}}^{x} f^{\prime}(t) d t \approx\left(x-y_{n}\right) f^{\prime}\left(y_{n}+\frac{1}{2}\left(x-y_{n}\right)\right) \\
& \int_{y_{n}}^{x} f^{\prime}(t) d t \cong\left(x-y_{n}\right) f^{\prime}\left(\frac{y_{n}+x}{2}\right) .
\end{aligned}
$$

Persamaan (7) disubstitusikan ke Persamaan (5) diperoleh :

$$
f(x)=f\left(y_{n}\right)+\left(x-y_{n}\right) f^{\prime}\left(\frac{x+y_{n}}{2}\right) .
$$

Misal $x=x_{n+1}$ dengan $f\left(x_{n+1}\right)=0$. Sehingga :

$$
x_{n+1}=y_{n}-\frac{f\left(y_{n}\right)}{f^{\prime}\left(\frac{x_{n+1}+y_{n}}{2}\right)},
$$

dengan

$$
y_{n}=x_{n}+\frac{f\left(x_{n}\right)}{f^{\prime}\left(x_{n}\right)}
$$

Karena Persamaan (8) memuat $x_{n+1}$ pada bagian $f^{\prime}$, maka dapat dimisalkan

$$
x_{n+1}=x_{n+1}^{*} \text {. }
$$

Nilai dari $x_{n+1}^{*}$ dapat diperoleh dengan metode Newton, yaitu :

Sehingga,

$$
x_{n+1}^{*}=x_{n}-\frac{f\left(x_{n}\right)}{f^{\prime}\left(x_{n}\right)} \text {. }
$$

$$
\begin{aligned}
\frac{x_{n+1}+y_{n}}{2} & =\frac{x_{(n+1)}^{*}+y_{n}}{2} \\
& =\frac{x_{n}-\frac{f\left(x_{n}\right)}{f^{\prime}\left(x_{n}\right)}+y_{n}}{2} \\
& =x_{n} .
\end{aligned}
$$


Jadi Persamaan (8) dapat disederhanakan menjadi dua langkah, yaitu [2]:

$$
\begin{gathered}
y_{n}=x_{n}+\frac{f\left(x_{n}\right)}{f^{\prime}\left(x_{n}\right)}, \\
x_{n+1}=y_{n}-\frac{f\left(y_{n}\right)}{f^{\prime}\left(x_{n}\right)} .
\end{gathered}
$$

\section{Konstruksi Modifikasi Metode Newton untuk Penyelesaian Sistem Persamaan Nonlinear}

Konstruksi modifikasi metode Newton untuk menyelesaikan sistem persamaan nonlinear dilakukan dengan pendekatan deret Taylor. Langkah pertama menentukan ekspansi deret Taylor dari $\mathbf{F}(\mathbf{X})$ disekitar $\mathbf{X}=\mathbf{X}_{n}$, yaitu

$$
\mathbf{F}(\mathbf{X})=\mathbf{F}\left(\mathbf{X}_{\boldsymbol{n}}\right)+\mathbf{F}^{\prime}\left(\mathbf{X}_{\boldsymbol{n}}\right)\left(\mathbf{X}-\mathbf{X}_{\boldsymbol{n}}\right)+\cdots+\frac{\mathbf{F}^{(\mathbf{n})}\left(X_{n}\right)}{n !}\left(X-X_{n}\right)^{n}+\cdots .
$$

Pilih $\mathbf{X}=\mathbf{X}_{n+1}$ dan $\mathbf{F}\left(\mathbf{X}_{n+1}\right)=\mathbf{0}$ sehingga

$$
\begin{aligned}
& \mathbf{F}\left(\mathbf{X}_{\mathbf{n}+1}\right)= \mathbf{F}\left(\mathbf{X}_{n}\right)+\mathbf{F}^{\prime}\left(\mathbf{X}_{n}\right)\left(\mathbf{X}_{\mathbf{n}+\mathbf{1}}-\mathbf{X}_{n}\right)+\cdots+\frac{\mathbf{F}^{(\mathbf{n})}\left(X_{n}\right)}{n !}\left(X_{n+1}-X_{n}\right)^{n}+\cdots \\
& \mathbf{0}= \mathbf{F}\left(\mathbf{X}_{n}\right)-\mathbf{F}^{\prime}\left(\mathbf{X}_{n}\right)\left(\mathbf{X}_{n}-\mathbf{X}_{n+1}\right)+\cdots+(-\mathbf{1})^{\mathbf{n}} \frac{\mathbf{F}^{(\mathbf{n})}\left(X_{n}\right)}{n !}\left(X_{n}-X_{n+1}\right)^{n}+\cdots \\
& \mathbf{F}\left(\mathbf{X}_{n}\right)= \mathbf{F}^{\prime}\left(\mathbf{X}_{n}\right)\left(\mathbf{X}_{n}-\mathbf{X}_{n+1}\right)-\frac{\mathbf{F}^{\prime \prime}\left(\mathbf{X}_{\mathbf{n}}\right)}{2 !}\left(\mathbf{X}_{n}-\mathbf{X}_{n+1}\right)^{\mathbf{n}}+\cdots+(-\mathbf{1})^{\mathbf{n}} \frac{\mathbf{F}^{(\mathbf{n})}\left(X_{n}\right)}{n !}\left(X_{n}-X_{n+1}\right)^{n} \\
& \quad+\cdots
\end{aligned}
$$

Kemudian mencari deret Taylor $\mathbf{F}\left(\mathbf{Y}_{\mathbf{n}}\right)$ disekitar $\mathbf{X}_{\mathbf{n}}$, yaitu

$$
\mathbf{F}\left(\mathbf{Y}_{n}\right)=\mathbf{F}\left(\mathbf{X}_{n}\right)+\mathbf{F}^{\prime}\left(\mathbf{X}_{n}\right)\left(\mathbf{Y}_{n}-\mathbf{X}_{n}\right)+\cdots+\frac{\mathbf{F}^{(\mathbf{n})}\left(\boldsymbol{X}_{n}\right)}{n !}\left(\boldsymbol{Y}_{n}-X_{n}\right)^{n}+\cdots
$$
dengan

Selanjutnya mencari $\mathbf{X}_{n+1}$

$$
Y_{n}=X_{n}+\left[J\left(X_{n}\right)\right]^{-1} F\left(X_{n}\right)
$$

$$
\begin{aligned}
\mathbf{F}\left(\mathbf{Y}_{n}\right) & =\mathbf{F}\left(\mathbf{X}_{n}\right)-\mathbf{F}^{\prime}\left(\mathbf{X}_{n}\right)\left(\mathbf{X}_{n}-\mathbf{Y}_{n}\right)+\cdots+(-\mathbf{1})^{\mathbf{n}} \frac{\mathbf{F}^{(\mathbf{n})}\left(X_{n}\right)}{n !}\left(X_{n}-Y_{n}\right)^{n}+\cdots \\
& =\mathbf{F}^{\prime}\left(\mathbf{X}_{n}\right)\left(\mathbf{Y}_{n}-\mathbf{X}_{n+1}\right)+\frac{\mathbf{F}^{\prime \prime}\left(\mathbf{X}_{n}\right)\left(\mathbf{Y}_{n}-\mathbf{X}_{n+1}\right)}{2 !}+\cdots+\frac{\mathbf{F}^{(\mathbf{n})}\left(X_{n}\right)}{n !}\left(Y_{n}-X_{n+1}\right)^{n}+\cdots \\
\mathbf{F}\left(\mathbf{Y}_{\mathbf{n}}\right) & =\mathbf{F}^{\prime}\left(\mathbf{X}_{\mathbf{n}}\right)\left(\mathbf{Y}_{\mathbf{n}}-\mathbf{X}_{\mathbf{n}+\mathbf{1}}\right)+\mathbf{O}\left(\mathbf{X}_{n}-\mathbf{Y}_{n}\right)^{2}
\end{aligned}
$$

Jika $\mathbf{O}\left(\mathbf{X}_{\boldsymbol{n}}-\mathbf{Y}_{\boldsymbol{n}}\right)^{\mathbf{2}}$ yang merupakan bentuk error yang diabaikan maka Persamaan (10) menjadi :

atau dapat ditulis :

$$
\begin{aligned}
{\left[\mathbf{F}^{\prime}\left(\mathbf{X}_{\mathbf{n}}\right)\right]^{-1} \mathbf{F}\left(\mathbf{Y}_{\mathbf{n}}\right) } & =\mathbf{Y}_{\mathbf{n}}-\mathbf{X}_{\mathbf{n}+\mathbf{1}} \\
\mathbf{X}_{\mathbf{n}+\mathbf{1}} & =\mathbf{Y}_{\mathbf{n}}-\left[\mathbf{F}^{\prime}\left(\mathbf{X}_{\mathbf{n}}\right)\right]^{-\mathbf{1}} \mathbf{F}\left(\mathbf{y}_{\mathbf{n}}\right),
\end{aligned}
$$

$$
X_{n+1}=Y_{n}-\left[J\left(x_{n}\right)\right]^{-1} F\left(y_{n}\right)
$$

\section{SIMULASI NUMERIK}

Pada sub bab ini diberikan simulasi numerik menggunakan software scilab dengan nilai galat toleransi $\left(E_{\delta}\right)$ yang diberikan adalah $10^{-15}$ untuk Persamaan (11) yang bertujuan untuk menunjukkan keefektifan persamaan tersebut. Sistem persamaan nonlinear yang digunakan adalah sebagai berikut:

Contoh 1

$$
\mathbf{F}_{\mathbf{1}}(\mathbf{X})=\left\{\begin{array}{l}
f_{1}(x, y)=2 x^{2}+y^{2}-7=0 \\
f_{2}(x, y)=x^{2}-5 y+2=0
\end{array}\right.
$$


dengan nilai awal $\left(x_{0}, y_{0}\right)=(1,1)$ dan galat toleransi $E_{\delta}=10^{-15}$, akan ditentukan penyelesaian dari Persamaan (11).

\section{Penyelesaian:}

Menentukan nilai iterasi pertama $\left(\mathbf{X}_{\mathbf{1}}\right)$ pada Persamaan (11) dengan modifikasi metode Newton adalah sebagai berikut:

Adapun langkah-langkah yang dilakukan yaitu:

Iterasi pertama

1. Nilai $\mathbf{X}_{\mathbf{0}}=\left[\begin{array}{l}1 \\ 1\end{array}\right]$ disubstitusikan ke dalam Persamaan (11) untuk mendapatkan nilai $\mathbf{F}\left(\mathbf{X}_{\mathbf{0}}\right)$, sebagai berikut:

$$
\begin{aligned}
\mathbf{F}\left(\mathbf{X}_{\mathbf{0}}\right) & =\left[\begin{array}{c}
2(1)^{2}+(1)^{2}-7 \\
(1)^{2}-5(1)+2
\end{array}\right] \\
& =\left[\begin{array}{l}
-4 \\
-2
\end{array}\right] .
\end{aligned}
$$

2. Mencari $\mathbf{J}\left(\mathbf{X}_{\mathbf{0}}\right)$ pada Persamaan (11) dengan mensubstitusikan nilai $\mathbf{X}_{\mathbf{0}}$ ke dalam $\mathbf{J}(\mathbf{X})$, sehingga diperoleh:

$$
\begin{aligned}
\mathbf{J}(\mathbf{X}) & =\left[\begin{array}{ll}
\frac{\partial f_{1}(x, y)}{\partial x} & \frac{\partial f_{1}(x, y)}{\partial y} \\
\frac{\partial f_{2}(x, y)}{\partial x} & \frac{\partial f_{2}(x, y)}{\partial y}
\end{array}\right] \\
& =\left[\begin{array}{cc}
4 x & 2 y \\
2 x & -5
\end{array}\right] . \\
\mathbf{J}\left(\mathbf{X}_{\mathbf{0}}\right) & =\left[\begin{array}{cc}
4(1) & 2(1) \\
2(1) & -5
\end{array}\right] \\
& =\left[\begin{array}{cc}
4 & 2 \\
2 & -5
\end{array}\right] .
\end{aligned}
$$

3. Setelah diperoleh nilai $\mathbf{J}\left(\mathbf{X}_{\mathbf{0}}\right)$, langkah selanjutnya yaitu mencari invers $\mathbf{J}\left(\mathbf{X}_{\mathbf{0}}\right)$, maka diperoleh:

$$
\begin{aligned}
\operatorname{det}\left(\mathbf{J}\left(\mathbf{X}_{\mathbf{0}}\right)\right) & =4 \cdot(-5)-2 \cdot 2 \\
& =-24 . \\
\operatorname{adj}\left(\mathbf{J}\left(\mathbf{X}_{\mathbf{0}}\right)\right) & =\left[\begin{array}{cc}
-5 & -2 \\
-2 & 4
\end{array}\right] . \\
\mathbf{J}^{-\mathbf{1}}\left(\mathbf{X}_{\mathbf{0}}\right)= & \frac{1}{\operatorname{det}\left(\mathbf{J}\left(\mathbf{X}_{\mathbf{0}}\right)\right)} \operatorname{adj}\left(\mathbf{J}\left(\mathbf{X}_{\mathbf{0}}\right)\right) \\
= & \frac{1}{-24}\left[\begin{array}{cc}
-5 & -2 \\
-2 & 4
\end{array}\right] .
\end{aligned}
$$

4. Hasil $\mathbf{J}^{\mathbf{- 1}}\left(\mathbf{X}_{\mathbf{0}}\right)$ digunakan untuk mendapatkan nilai $\mathbf{Y}_{\mathbf{0}}$, sehingga diperoleh:

$$
\begin{aligned}
\mathbf{Y}_{\mathbf{0}} & =\mathbf{X}_{\mathbf{0}}+\mathbf{J}^{\mathbf{- 1}}\left(\mathbf{X}_{\mathbf{0}}\right) \mathbf{F}\left(\mathbf{X}_{\mathbf{0}}\right) \\
& =\left[\begin{array}{l}
1 \\
1
\end{array}\right]+\frac{1}{-24}\left[\begin{array}{cc}
-5 & -2 \\
-2 & 4
\end{array}\right]\left[\begin{array}{l}
-4 \\
-2
\end{array}\right] \\
& =\left[\begin{array}{l}
0 \\
1
\end{array}\right] .
\end{aligned}
$$

5. Nilai $\mathbf{Y}_{\mathbf{0}}=\left[\begin{array}{l}4 \\ 6\end{array}\right]$ disubstitusikan ke dalam Persamaan (11) untuk mendapatkan nilai $\mathbf{F}\left(\mathbf{Y}_{\mathbf{0}}\right)$, sebagai berikut:

$$
\begin{aligned}
\mathbf{F}\left(\mathbf{Y}_{\mathbf{0}}\right) & =\left[\begin{array}{c}
2(0)^{2}+(1)^{2}-7 \\
(0)^{2}-5(1)+2
\end{array}\right] \\
& =\left[\begin{array}{l}
-6 \\
-3
\end{array}\right] .
\end{aligned}
$$


6. Hasil $\mathbf{F}\left(\mathbf{Y}_{\mathbf{0}}\right)$ digunakan untuk mendapatkan nilai $\mathbf{X}_{\mathbf{1}}$ sehingga iterasi pertama untuk Persamaan (11) diperoleh sebagai berikut:

$$
\begin{aligned}
\mathbf{X}_{\mathbf{1}} & =\mathbf{Y}_{\mathbf{0}}-\mathbf{J}^{-\mathbf{1}}\left(\mathbf{X}_{\mathbf{0}}\right) \mathbf{F}\left(\mathbf{Y}_{\mathbf{0}}\right) \\
& =\left[\begin{array}{l}
0 \\
1
\end{array}\right]-\frac{1}{-24}\left[\begin{array}{cc}
-5 & -2 \\
-2 & 4
\end{array}\right]\left[\begin{array}{l}
-6 \\
-3
\end{array}\right] \\
& =\left[\begin{array}{c}
1,5 \\
1
\end{array}\right] .
\end{aligned}
$$

Setelah diperoleh nilai $\mathbf{X}_{\mathbf{1}}$, langkah selanjutnya yaitu mencari nilai galat dari Persamaan (11). Pada penelitian ini galat ditentukan menggunakan galat iterasi dan norm galat.

1. Adapun galat iterasi sebagai berikut:

$$
\begin{aligned}
\mathbf{E}_{1} & =\mathbf{X}_{1}-\mathbf{X}_{\mathbf{0}} \\
& =\left[\begin{array}{c}
1.5 \\
1
\end{array}\right]-\left[\begin{array}{l}
1 \\
1
\end{array}\right] \\
& =\left[\begin{array}{c}
0.5 \\
0
\end{array}\right] .
\end{aligned}
$$

2. Setelah galat iterasi diperoleh maka langkah selanjutnya adalah mencari nilai norm galat.

$$
\begin{aligned}
\left\|\mathbf{E}_{\mathbf{1}}\right\| & =\sqrt{\left(x_{1}-x_{0}\right)^{2}+\left(y_{1}-y_{0}\right)^{2}} \\
& =\sqrt{(0.5)^{2}+(0)^{2}} \\
& =0.5 .
\end{aligned}
$$

karena nilai norm galat pertama $\left\|\mathbf{E}_{\mathbf{1}}\right\|>E_{\delta}$ maka iterasi dilanjutkan, untuk hasil dari iterasi kedua dan seterusnya dilakukan dengan menggunakan bantuan program scilab. Adapun hasil semua iterasi dapat dilihat pada Tabel 1 berikut ini:

Tabel 1 Hasil Iterasi $F_{1}(X)$

\begin{tabular}{|c|c|c|c|}
\hline \multirow{2}{*}{ Iterasi ke- $n$} & \multicolumn{2}{|c|}{$\boldsymbol{X}_{n}$} & \multirow{2}{*}{$\left\|\mathbf{E}_{\mathbf{n}}\right\|$} \\
\cline { 2 - 4 } & $x$ & $y$ & 0,5 \\
\hline 1 & 1,5 & 1 & 0,2291666671 \\
\hline 2 & 1,729166667 & 1 & 0,002884137 \\
\hline 3 & 1,732050804 & 1 & 0,0000000036 \\
\hline 4 & 1,7320508076 & 1 & 0 \\
\hline 5 & 1,7320508076 & 1 & \\
\hline
\end{tabular}

Tabel 1 menunjukkan hasil semua iterasi dari solusi sistem persamaan nonlinear pada Persamaan (11) dengan iterasi sebanyak lima kali dengan solusi akhir yang didapat yaitu untuk $x=$ 1,7320508076 dan $y=1$. Perhitungan galat pada iterasi $x_{n}$ dan galat pada iterasi $y_{n}$. Kedua galat iterasi tersebut digunakan untuk mendapatkan nilai $\left\|\mathbf{E}_{\mathbf{n}}\right\|$, yang mana dalam penyelesaian untuk mendapatkan nilai galat didefinisikan sebagai berikut:

$$
\left\|\mathbf{E}_{\mathbf{n}}\right\|=\sqrt{\left(x_{n}-x_{n-1}\right)^{2}-\left(y_{n}-y_{n-1}\right)^{2}} .
$$

Iterasi akan berhenti jika nilai $\left\|\mathbf{E}_{\mathbf{n}}\right\|$ kurang dari galat toleransi yang diberikan yaitu $10^{-15}$. Nilai awal $\mathbf{X}_{\mathbf{0}}$ pada Persamaan (11) iterasi norm galat berhenti pada iterasi kelima yaitu dengan nilai $\left\|\mathbf{E}_{\mathbf{n}}\right\|=0$. 
Contoh 2

$$
\mathbf{F}_{2}(\mathbf{X})=\left\{\begin{array}{l}
f_{1}(x, y)=x^{2}-10 x+y^{2}+8=0 \\
f_{2}(x, y)=x y^{2}+x-10 y+8=0
\end{array}\right.
$$

dengan nilai awal $\left(x_{0}, y_{0}\right)=(0,0)$ dan galat toleransi $E_{\delta}=10^{-15}$, akan ditentukan penyelesaian dari Persamaan (12).

\section{Penyelesaian:}

Dengan cara yang sama diperoleh hasil semua iterasi Persamaan (12).

Tabel 2 Hasil Iterasi $\mathbf{F}_{\mathbf{1}}(\mathbf{X})$

\begin{tabular}{|c|c|c|c|}
\hline \multirow{2}{*}{ Iterasi ke- $n$} & \multicolumn{2}{|c|}{$\boldsymbol{X}_{n}$} & \multirow{2}{*}{$\left\|\mathbf{E}_{\mathbf{n}}\right\|$} \\
\cline { 2 - 4 } & $x$ & $y$ & 1,2565240939 \\
\hline 1 & 0,94144 & 0,832192 & 0,1766778551 \\
\hline 2 & 0,999480241 & 0,999064391 & 0,0010702862 \\
\hline 3 & 1,0000000002 & 0,9999999993 & 0 \\
\hline 4 & 1 & 1 & 0,0000000000280109 \\
\hline 5 & 1 & 1 & \\
\hline
\end{tabular}

Tabel 2 menunjukkan hasil semua iterasi dari solusi sistem persamaan nonlinear pada Persamaan (12) dengan iterasi sebanyak lima kali dengan solusi akhir yang didapat yaitu untuk $x=1$ dan $y=1$. Perhitungan galat pada iterasi $x_{n}$ dan galat pada iterasi $y_{n}$. Kedua galat iterasi tersebut digunakan untuk mendapatkan nilai $\left\|\mathbf{E}_{\mathbf{n}}\right\|$, yang mana dalam penyelesaian untuk mendapatkan nilai galat didefinisikan sebagai berikut:

$$
\left\|\mathbf{E}_{\mathbf{n}}\right\|=\sqrt{\left(x_{n}-x_{n-1}\right)^{2}-\left(y_{n}-y_{n-1}\right)^{2}} .
$$

Iterasi akan berhenti jika nilai $\left\|\mathbf{E}_{\mathbf{n}}\right\|$ kurang dari galat toleransi yang diberikan yaitu $10^{-15}$. Nilai awal $\mathbf{X}_{\mathbf{0}}$ pada Persamaan (12) iterasi norm galat berhenti pada iterasi kelima yaitu dengan nilai $\left\|\mathbf{E}_{\mathbf{n}}\right\|=0$.

\section{KESIMPULAN}

Berdasarkan hasil dan pembahasan yang telah dipaparkan, dapat disimpulkan bahwa:

1. Modifikasi Metode Newton digunakan untuk menyelesaikan sistem persamaan nonlinear, dengan rumus:

$$
\begin{aligned}
& Y_{n}=X_{0}+J^{-1}\left(X_{0}\right) F\left(X_{0}\right) \\
& X_{n}=Y_{0}-J^{-1}\left(X_{0}\right) F\left(Y_{0}\right)
\end{aligned}
$$

2. Hasil penelitian dari modifikasi metode Newton dengan kenvergensi orde tiga dapat menyelesaikan sistem persamaan nonlinear. Adapun langkah-langkah dalam menyelesaikan sistem persamaan nonlinear dengan menggunakan modifikasi metode Newton adalah sebagai berikut:

1) Diberikan sistem persamaan nonlinear dengan titik awal $\mathbf{X}_{\mathbf{0}}$ dan $E_{\delta}$ sebagai galat toleransi.

2) Hitung $\mathbf{F}\left(\mathbf{X}_{\mathbf{0}}\right)$ dan $\mathbf{J}^{-\mathbf{1}}\left(\mathbf{X}_{\mathbf{0}}\right)$.

3) Hitung $\mathbf{Y}_{\mathbf{0}}$ dan $\boldsymbol{F}\left(\boldsymbol{Y}_{\mathbf{0}}\right)$.

4) Hitung $\mathbf{X}_{\mathbf{n}}=\mathbf{Y}_{\mathbf{0}}-\mathbf{J}^{-\mathbf{1}}\left(\mathbf{X}_{\mathbf{0}}\right) \mathbf{F}\left(\mathbf{Y}_{\mathbf{0}}\right)$

5) Jika $\left\|\mathbf{E}_{\mathbf{n}}\right\| \geq E_{\delta}$, maka lanjut ke langkah selanjutnya yaitu ganti nilai $\mathbf{X}_{\mathbf{0}}=\mathbf{X}_{\mathbf{n}}, n=1,2,3, \ldots$ dan kembali ke langkah 4. Jika $\left\|\mathbf{E}_{\mathbf{n}}\right\|<E_{\delta}$, maka diperoleh $\mathbf{X}_{\mathbf{n}}$ solusi dari sistem persamaan nonlinear 


\section{DAFTAR PUSTAKA}

[1] Mathew J H. Numerical Methods for Mathematics, Science, and Engineering, Ed ke-2, PrenticeHall, New Jersey. 1992.

[2] Kou J, Li Y, dan Wang X. A Modification of Newton Method with Third-Order Convergence, Appl. Math. Comput. 2006; 181(2): 1106-1111.

[3] Burden R L. Numerical Analysis,Ed ke-8. USA: Thomson. 2005.

[4] Dugopolski, Mark. Elementary and Intermediate Algebra, second edition. New York: McGrawHill. 2006.

[5] Utami N N R, Widana I N, dan Asih N M. Perbandingan Solusi Sistem Persamaan Nonlinear Menggunakan Metode Newton dan Metode Jacobian, E-Jurnal Matematika, 2013; 2(2):11-17.

[6] Munir R. Metode Numerik, Informatika, Bandung. 2015.

YULI RAHAYU : Jurusan Matematika FMIPA UNTAN, Pontianak yulirahayu@student.untan.ac.id

EVI NOVIANI $\quad$ : Jurusan Matematika FMIPA UNTAN, Pontianak evi_noviani@math.untan.ac.id

YUDHI : Jurusan Matematika FMIPA UNTAN, Pontianak yudhi@ math.untan.ac.id 